\title{
Interviews and Questionnaires as Legal Research Instruments
}

\author{
Michael Sunday Afolayan ${ }^{1 *} \quad$ Omolade Adeyemi Oniyinde, Ph.D ${ }^{2}$ \\ 1.Business \& Industrial Law Department, Faculty of Law, Ekiti State University, Ado-Ekiti, Nigeria \\ 2.Public Law Department, Faculty of Law, Ekiti State University, P.M.B. 5363, Ado-Ekiti, Nigeria
}

\begin{abstract}
This work is an inquiry into the duo instrumentalities of research namely; interview and questionnaire in the field of legal research. It focused on issues such as nature, usefulness, types, advantages, disadvantages, reliability as research instruments, as well as the comparison of the two instrumentalities. The essence of this work is to expose to legal researchers the 'pros' and 'cons' of this instruments and their multidimensional ramifications in serving as better tools for more effective and fruitful legal research venture. In carrying out this work, doctrinal approach was adopted by looking at the existing literatures in the field of legal research and examining the extent, if any, to which the survey method of research is embraced by lawyers and legal researchers to improve on the outcome of their research and to reflect the reality or impact of law on the society. It was discovered that what a traditional legal researcher does is to organise his study around legal propositions; use court reports and conventional legal materials which are readily assessable in a law library as his principal sources of data, and draws conclusion from these legal materials. ${ }^{1}$ The recent trend, however, is to move beyond or away from the desk and gather information from the field in order to have more social and realistic input in legal research. This has widened the scope of legal research methodology but the fact remained that the methods and strategy adopted for any particular research project will depend on the subject matter. ${ }^{2}$ In conclusion, this work provides the basic guides in the selection, construction and administration of questionnaire and interview as research instruments. Their uses and limitations, as well as their construction in terms of the structure and content were also discussed. The response rate as well as the quality of information acquire will depend on the subject matter of research, the choice of the researcher and the extent to which the suggestions in this work are utilised.
\end{abstract}

Keywords: Legal, Research, Interviews, Questionnaires, Instruments.

DOI: $10.7176 / \mathrm{JLPG} / 83-08$

Publication date:March $31^{\text {st }} 2019$

\section{Introduction}

Research is defined as a systematic search for facts or scientific investigation of principles and facts of any subject, based on original and first-hand study of authorities or experiment. ${ }^{3}$ It involves searching into a matter closely and carefully. It is an inquiry directed at the discovery of truth. ${ }^{4}$

Three characteristics of research include the fact that, first, research is systematic and controlled, basing its operation on the inductive-deductive model against experience whose event occurs in a haphazard manner. Second, research is empirical; that is, experience is used for validation. Subjective belief must be checked against objective reality. Third, research is self-correcting; there are inbuilt mechanisms to protect the researcher from error and his procedure and results are open to other professionals through revision or rejection of incorrect result in time. Fourth, research is a combination of experience and reasoning, and it is regarded as the most successful approach to the discovery of truth. ${ }^{5}$

However, no research is purely new, as even original discoveries are an extension of the search already undertaken, being showed generally as expressing agreement or refutation or plain addition. ${ }^{6}$ In Rajkumari Agrawala's words; ${ }^{7}$

Research is a continuum... Research is the gathering of evidence or information for ascertaining an assumption or verifying some hypothesis. It is an inquiry for the verification of a fresh theory or for supplementing prevailing theories by new knowledge.

A researcher therefore owes it a duty to examine works prevailing in his area of research and is burdened with the heritage of information already collected in his area of work.

\footnotetext{
${ }^{1}$ Aboki, Y., "Introduction to Legal Research Methodology", Second Edition, (Tamaza Publishing Co.Ltd, Zaria 2009) p.3

${ }^{2}$ Gasiokwu, M.O.U., "Legal Research Methodology", (Chenglo Ltd, Enugu, 2004) pg 3.

${ }^{3}$ Worthley, B.A., "Some Reflections on Legal Research after Thirty Years" Silver Jubilee of the Indian Law Institute Publication No. 7, Legal Legal Research Methodology (1983) 2.

${ }^{4}$ Ayua, I.A., "Legal Research and Development" in Ayua, I.A. \& Guobadia D.A. (eds), Law and Research Methodology (NIALS, Lagos, 2001).

${ }^{5}$ Babarinde, S.A., "The Link Between Everyday Reasoning, Scientific Reasoning, Scientific Research and Theory", in Methodology of Basic Basic and Applied Research (2 ${ }^{\text {nd }}$ ed), (Postgraduate School, University of Ibadan Publication, Ibadan, 2006.

${ }^{6}$ Gasiokwu, M.O.U., "Legal Research Methodology”, (Chenglo Ltd, Enugu, 2004) pg 3.

${ }^{7}$ Ibid.
} 


\section{The Concept of Legal Research Methodology}

According to Aboki, ${ }^{1}$ legal research is a problem solving process and research method is the process whereby materials relevant to a given situation are identified, gathered, stored and retrieved for use.

In legal research, therefore, what a legal researcher does is to organise his study around legal propositions; use court reports and conventional legal materials as his principal sources of data readily assessible in a law library; and draws conclusion from these legal materials. ${ }^{2}$ The recent trend, however, is to move beyond or away from the desk and gather information from the field in order to have more social and realistic input in legal research. This has widened the scope of legal research methodology but the fact remained that the methods and strategy adopted for any particular research project will depend on the subject matter. ${ }^{3}$

If we dig in the garden, we use a spade, if we search for oil; we employ a rock-drill. In other words, the choice of tool depends on the depth to which we intend to probe. ${ }^{4}$

We now turn to briefly examine types of Legal Research.

\section{Types of Legal Research}

As stated earlier, legal research is of different types and any type that is employed depend on the focus and modalities adopted in eliciting information on a phenomenon for purposes of formal analysis. The common types however are;

\section{i. Historical Research}

This type of research is aimed at describing legal enactments, statutes or institutions in their unique historical perspectives. Historical research is desirable especially when it becomes necessary to find out the previous law in order to understand the reason behind the existing law and the course of its evolution. It often show that a particular existing provision of the law that was justifiable at the time when it was introduced is no longer justifiable because the reason that justified the original inclusion of that provision are no longer valid. In this circumstance, the researcher must consult earlier commentaries on the particular statute. The major problem attendant upon this type of research concerns the difficulty of obtaining the accurate and detailed records one wishes to examine. ${ }^{5}$

\section{ii. Analytical Research}

This type of research aims primarily at an exploration of what is the existing law with the view or objective of discovering whether they are meeting the interest of the society. In a federal structure like Nigeria, for example, analytical research will explore both federal and state laws on any given subject especially if that subject is within the concurrent list in the Constitution. A good researcher must therefore know the legislative competence of the legislative bodies within a federal set-up. Conclusions reached therefrom are helpful in bringing about legal reforms

It is notable however, that at times; there may be conflicts of judicial decisions. A researcher must devote attention to such conflicts because they may lend support to his suggestions for a clarification of law or possibly reform the law.

\section{iii. Comparative Research}

This involves study of the laws of different countries on any given subject matter whether for the purpose of law reform in the country or for determining the justifiability of any legal precept existing in one State as against the practice of other States. Comparative research is often propelled by the need for legal reform in the country where the reform is being carried out. It is done by basically comparing the laws of several countries. Legislature imitates each other and law reform bodies try to learn from each other's experience. The main problem that may face the researcher who engages in comparative research is, what countries to choose for study, what books and other materials to consult and how much of the materials collected to be used for the purpose of the research project. $^{6}$

\section{iv. Ethnographic Research}

This is primarily concerned with studying groups and subgroups that make the cultural primitive societies. In the context of a legal research, such study will perhaps evaluate or study the adequacy of the knowledge of the existing laws and legal instruments, and impacts, if any, that such have made on the concerned primitive or local communities. ${ }^{7}$ An ethnographic research takes cognisance of the preferences, assumptions, practices and conventions of the people. An indispensable method that guarantees success in this type of research is participant

\footnotetext{
${ }^{1}$ Aboki, Y., "Introduction to Legal Research Methodology", Second Edition, (Tamaza Publishing Co.Ltd, Zaria 2009) p.3

${ }^{2}$ Ibid at p. 3

${ }^{3}$ Gasiokwu M.O.U., Op.Cit at p.5

${ }^{4}$ George Schwarzenberger, "Reflections on the Law of International Institutions" 13 Current Legal Problems 1960,276 at 289

${ }^{5}$ Olomolaiye, F., Research Methods and Statistics, Jos: 1986, p. 8

${ }^{6}$ Gasioukwu, M.O.U., Op.Cit at p.8

${ }^{7}$ Akomolede, T.I., “Types of Legal Research” M.Phil, Ph.D. Class of Legal Research Methodology Lecture notes, Tuesday $12^{\text {th }}$ January 2016.
} 
observation and also a careful study of legal materials written or available in such communities. ${ }^{1}$

\section{v. Statistical Research}

This involves the gathering of statistics which will give an idea of the actual working of the law. It provides quantitative illustrations of the dynamics of certain social process or serves to arrange the sets of available data in numerical terms. It involved collection of data in a methodological manner

However, because it involves quantitative analysis, it is not a popular way of conducting legal research. It involves going to the field to collect data through surveys, opinion polls, participant observation, focused group discussion, and relies on instrument such as interviews and questionnaires.

A way of overcoming the above identified challenges is by employing interdisciplinary approach or embracing academic collaborations so that persons who are knowledgeable in quantitative or numerical aspects of the research are brought in to carry out the analysis, while the legal researcher is left to draw the inferences and write his conclusions based on results of the analysis.

\section{Research Instruments}

Research instruments are the tools for data collection. There are two main methods of doing this which are;

i. Survey Methods; and,

ii. Non-Survey Methods

The survey method is one which entails direct contact between the researcher and the subject, during which the researcher asks questions which are answered by the subject.

The non-survey method on the other hand is one in which data is collected about subject without necessarily asking them questions and without necessarily involving any direct contact between the researcher and the subject. Our focus in this paper is on the survey method of data collection. It is notable however that non-survey data collection method includes; Experiments, Observation, Case studies, and Document Studies. ${ }^{2}$

The survey method of data collection is achieved through the administration of two main types of instruments, namely; the questionnaire and the Interview Schedule. Our main focus here is to examine the use of interviews and questionnaire as research instruments. Obviously, these two tools fall within the category of nondoctrinal research also known as empirical research as both instruments involve the collection of fact and data from the target audience. It is intended to treat the two instruments separately here, and then compare the two subsequently.

\section{Meaning, Scope and Purpose of Interview}

Interviews consist of collecting data by asking question. It is a research method that involves the researcher asking questions and hopefully receiving answers from the respondents. ${ }^{3}$ It is an interaction in which oral questions are posed by the interviewer to elicit response from the interviewee.

Interview is not just asking and answering questions, it is beyond the oral aspect which the interviewer may observe the interviewee behaviour, personality, opinion, way of thinking and beliefs. This type of research method can elicit truth by observing the interviewee expression with the question he is being asked.

The purpose of research interview is to explore the views, experience, beliefs of the individual participant on the information chosen. Interviews are also appropriate for exploring sensitive topics, where participant may not want to talk about sensitive issues especially where detailed insights are required. ${ }^{4}$

\section{Characteristics of Interview}

1. The participants, that is, the interviewer and the respondents are strangers. Thus, the investigator has to get himself introduced to the respondent in an appropriate manner.

2. The relationship between the participants and the interviewer is a transitory one. It has a fixed beginning and terminating points.

3. Interview is not a mere casual conversational exchange, but a conversation with a specific purpose, which include obtaining information relevant to a study.

4. Interview is a mode of obtaining verbal answers to questions put verbally.

5. The interaction between the interviewer and the respondent need not necessarily be on a face to face basis because interviews can be conducted over the telephone also.

6. Interview is not limited to a single respondent; it can also be conducted with a group of persons.

The fundamental purpose of the research is to listen attentively to what the respondents have to say, in order to

\footnotetext{
${ }^{1}$ ibid

${ }^{2}$ Soyombo, Omololu, "Selection of Research Instruments, Questionnaire, Design and Administration" In Readings in Law and Research Methodology, I.A.Ayua and D.A. Guobadia (eds.) Lagos, Nigeria: Nigerian Institute of Advanced Legal Studies. 2001, pg 103.

${ }^{3}$ Khushal R., and Filipos A., 'Legal Research Methods Teaching Materials', prepared under the Sponsorship of the Justice and Legal System Research Institute, 2009 pg. 162.

${ }^{4}$ Silverman D., "Doing Qualitative Research", London: Sage Publications, 2000, Pg. 15.
} 
acquire more knowledge about the study topic. ${ }^{1}$

It is imperative to ask questions that are likely to yield as much information about the study topic when carrying out interviews. It is usually best to start with questions that the participant can answer easily and then proceed to more difficult and sensitive topics. ${ }^{2}$ The length of interview varies, depending on the topic, researcher and participant. Averagely, the interview may last 20-60 minutes. ${ }^{3}$

\section{Types of Interviews}

There are three major types of interviews, they are;

(a) Fully-Structured interview

(b) Semi-Structured Interview

(c) Unstructured Interview ${ }^{4}$

(a) The Fully-Structured Interview

This is sometimes called a standardised interview. This is an interview made with a detailed standardised schedule. The same questions are put to all respondents and in the same order. The standardisation of the question enhances comparison between respondent's answers ${ }^{5}$ and the questions are usually very specific and often the interviewee has a fixed range of answers. The fully-structured interview is similar to questionnaire method. The difference between the two is that in structured interview, the questions are asked verbally.

\section{Sample}

If you were to consider the level of your education would you say you are happy or unhappy with yourself?

Very happy

Fairly happy

Not very happy

Not at all happy

Can't choose

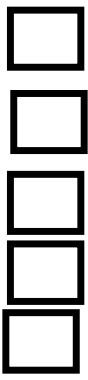

(b) The Semi-unstructured Interview

This type of interview has predetermined questions but the questions wording can be modified subject to the discretion of the interviewer, especially where the questions seem to be inappropriate with a particular interviewee. ${ }^{6}$ Ability to change the wordings makes it flexible and this gives some control over the interview to the interviewee. It also allows the interviewer to probe the interviewee ${ }^{7}$ since the subject area are predetermined and known to the interviewer, it enables him to ask relevant question to elicit adequate information necessary on the subject area. This type of interview is often used in radio and television interviews.

(c) The Unstructured Interview

This type of interview does not make use of any detailed pre-planned schedule or structure. It is the most flexible type of interview. ${ }^{8}$ The interviewer encourages the respondent to talk freely and extensively about a given topic with a minimum guidance. There is more freedom in the interaction of both the interviewer and the respondent(s). The limitation in this area is that the responses may not be comparable since questions asked of different interviewees will be different and the questions would have been framed in different ways since they are not standardised. ${ }^{9}$ For example, talking about satisfaction, are you satisfied with your life?

\section{Developing a Successful Interview Process}

Respondents should be informed about the study details before an interview takes place. Ideas of what is expected from the interview must be made known to him beforehand. This forms a fundamental aspect of the informed consent process. ${ }^{10}$

There are some factors an interviewer needs to consider to have a qualitative interview. These are;

\footnotetext{
${ }^{1}$ Kvale S., 'Interviews' Thousand Oaks: Sage Publications 1996, pg. 7.

${ }^{2}$ Britten N., "Qualitative interviews in Healthcare" In Pope C. \& Mays N., (eds.) Qualitative Research in Healthcare, $2^{\text {nd }}$ ed., London: BMY Books, 1999, Pp11-19

${ }^{3}$ Brillen H., (supra)/Ibid

${ }^{4}$ Khushal R., and Filipos A., Op.cit. at pg. 8

${ }^{5}$ Soyombo, op.cit.

${ }^{6}$ Khushal K. et al. op.cit

${ }^{7}$ Soyombo op.cit.

${ }^{8}$ ibid

${ }^{9}$ Soyombo, op.cit.

${ }^{10}$ Britten N., op.cit
} 
(i) Good Location - interviews should be conducted in areas free from distractions and a location most suitable for participants. ${ }^{1}$

(ii) Having a good rapport with participant prior to the interview as this may elicit positive effect on the subsequent development of the interview.

(iii) The interviewer requires listening skills and techniques to ensure that comprehensive and representative data are collected during the interview. ${ }^{2}$

(iv) Putting questions in a straight-forward, clear and non-threatening way. ${ }^{3}$ The interviewers must possess stable temperament; they must not be persons who lose their temper easily especially when the participants are not giving correct responses.

(v) Adopting open and emotional-neutral body language, nodding, smiles, looking interested and making encouraging noises (e.g. $\mathrm{hmm}$ ) during the interview. ${ }^{4}$

(vi) Asking all pertinent questions slowly and clearly and give interviewees sufficient time to respond.

(vii) Employing the opportunity to probe for more information or clarification whenever it appears there is ambiguity in the response of the respondent, the interviewer should be able to probe him. The main objective of probe is to elicit an understandable response wherever the respondent provides incomplete answers or irrelevant answers. Some probing questions include - "what do you mean (by that)?", 'Can you shed more light on that?, "what happened?", “anything more?”, "would you go over that again? Etc.

(viii) The interviewers should avoid long questions, leading questions and biased questions, e.g., 'do you think the constitution amendment is cumbersome?' Instead of - 'how do you find the process of constitution amendment?' Or what do you think of the process to amend the constitution?

(ix) Concluding the Interview; at the end of the interview, it is important to thank the participants and ask them if there is anything they would like to add.

\section{Adantages and Disadvantages of Interviews. \\ Advantages of Interview}

i. Interview is flexible and adaptable to individual situations. Interviews give researchers the opportunity to repeat or reframe questions where the Respondents are not getting the questions right.

ii. There is opportunity to probe, to encourage more complete and better explained responses.

iii. There is opportunity to explain or clarify questions and this increases the accuracy of the data collected.

iv. Interview is useful for gaining insight and context into a topic.

v. It allows for more control over the order and flow of questions.

vi. It tends to bring a higher response rate than the questionnaire. The interviewer can use the benefit of his/her presence to persuade respondents to cooperate. ${ }^{6}$

vii. There is total control over the environment. The interviewer can ensure that the interview is conducted in private such that no other person may constitute bias to the response of the respondent. ${ }^{7}$

viii. It increases the knowledge of both the interviewer and the interviewee. They can interchange their views and ideas.

ix. Sufficient information can be collected through the interview process.

\section{Disadvantages of Interviews}

i. Time Consuming - time constraint is one of the major limitations of the interview process. Preparation for the interview, taking the interviews and interpretation of the responses requires more time.

ii. Costly- interview method is expensive.

iii. Not suitable for personal matters as interviewee may not reveal his personal matters.

iv. It is susceptible to interview bias. There is possibility that the interview process can be influenced by the biases of the interviewer sometimes.

v. Lack of proper training of the Interviewer may affect the quality of the interview. The interviewer may not have good knowledge of the subject matter.

\section{Questionnaire as a Research Instrument}

A questionnaire can simply be described as a set of written questions which are served on respondents and which

\footnotetext{
${ }^{1}$ Kvale, S., interviews, op.cit.

${ }^{2}$ Hammersley, M., Atkinson, P., "Ethnography: Principles in Practice”, 2 ${ }^{\text {nd }}$ ed., London. Routledge, 1995, P.9

${ }^{3}$ Khushal V., op.cit.

${ }^{4}$ Britten, N., op.cit

${ }^{5}$ Soyombo O., op.cit.

${ }^{6}$ ibid

${ }^{7}$ ibid
} 
are completed by them. ${ }^{1}$ It is a written list of questions that are answered by a number of people so that information can be collected from the answers. Questionnaire is the most commonly used method of gathering information about use and users. It is easy to prepare but it is surprisingly easier to prepare a bad one. A researcher must be able to avoid major pitfalls in them and be able to identify them in the research done by others.

Questionnaire simply suggest a collection and, or a form containing a set of questions addressed to a statistically significant audience for which responses (information) are elicited for a survey. Researchers adopt this pattern when the intention is to determine the extent to which respondents hold a particular view or attitude. ${ }^{2}$ Questionnaire is a less expensive way to gather information (data) from a potentially large number of respondents in a survey study especially. ${ }^{3}$

Before the decision to use a questionnaire by a researcher from either the behavioural sciences and or humanities is reached, the following facts should be considered;

i. The aim/purpose (objectives) of the study;

ii. Active search and review of literature in relation to the intended study area/focus;

iii. What is the research vacuum that the present study sought to fill;

iv. Find out through a random opinion survey current views on the problem area; and,

v. Compare the opinion survey with the information from related studies (or literature) before the actual construction of the questionnaire is done. ${ }^{4}$

\section{Relevance of Questionnaire as a Research Instrument}

The questionnaire is a powerful evaluation tool in behavioural sciences. If well designed, it can be a very reliable, variable and optional tool;

a. to complement facts emanating from either diagnosis and or clinical findings;

b. to validate the authenticity of a statement, findings for generalisation etc.;

c. when rigorous experimentation cannot be adopted (i.e. intervention studies are not needed);

d. when information is needed from a large audience or participants to facilitate statistical analysis of results from opinion survey;

e. To correlate performance and perhaps, satisfaction with a test system among different group of users especially if the questionnaire has sections on demographic questions about the participants;

f. If the issues do not concern internal but external validity;

g. Necessary for testing hypothesis (statistical hunches) to establish the continuous relevance of a theory;

h. To corroborate other findings;

i. When both resources and time are inadequate; and,

j. To protect the identity or privacy of the respondents. ${ }^{5}$

\section{Types of Questionnaires}

Questionnaires could be structured or unstructured. A structured questionnaire is designed in advance and in a systematic manner. Under this type, questions are either open-ended or in a closed form. On the other hand, unstructured questionnaire are likely close interview guide. Questions are usually framed during the course of the interview. This is very rewarding when properly used because an interviewer is free to arrange the sequence of the questions to be asked. Encounter with respondents is flexible and there is the possibility of eliciting confidential information from the respondent. ${ }^{6}$

\section{The Open-Ended Format of Structured interview}

As the name implies, the open-ended format constitute the unrestricted and sometimes endless views or opinions of a respondent or group of participants in a study expressed in the space provided in the questionnaire.

The open-ended format are used when the researcher wants the respondent to respond in their own words and, or when the researcher does not know all of the possible alternative responses. The open-ended format can additionally provide the researcher the opportunity for correcting an already ingrained beliefs in the respondents by way of intervention studies. It is equally notable that in this format, there are no predetermined set of responses and the participants are free to answer in what manner they choose. It easily provides a rich

\footnotetext{
${ }^{1}$ Soyinka Omololu, Op Cit

${ }^{2}$ Osiki, J.O., "Use of a Research Questionnaire" in Methodology of Basic and Applied Research op. Cit. pp. 133-149 at pg. 133

${ }^{3}$ Ibid at p. 3

${ }^{4}$ Ibid, at p. 135

${ }^{5}$ Ibid at p. 135

${ }^{6}$ Gasiokwu M.O.U., Op Cit. at p.99
} 
opportunity for wide variety of responses including obtaining confidential information from the respondent. ${ }^{1}$

\section{The Close-Ended Format of Structured Interview}

The close-ended items are used when there are fixed number of alternative responses. In adopting this format, the respondents are asked to select an answer from among a list provided by the researcher. In survey studies especially, the close-ended questions are particular popular because they provide a greater uniformity of responses and are also easily processed. Unlike the open-ended, the responses from survey utilising the closeended questions are easily transferred directly into the computer format for analysis. The ease with which information from the close-ended format are utilized facilitates the usage of the fixed response format called "Likert Scale".

'Likert Scales' are list of statements on which respondents indicate whether they "agree", "strongly agree", "disagree" or "strongly disagree". Structured, fixed-response items are favourably adopted when the question has a fixed number of responses and the participant (or respondent) is to choose the one closest to the right one. The close-ended format has the advantage of simplifying the respondent's task as well as the researcher's analysis of results. $^{2}$

\section{Guidelines for the Construction of Questionnaire}

The following items have been identified as necessary for the construction of questionnaire; ${ }^{3}$

a) The vocabulary chosen should be simple and within the easy grasp of the least intelligent of the respondents;

b) The syntax should be clear and straight-forward. Long and complex sentences that required extended concentration on the part of the respondent defeat their purpose;

c) Professional jargon and technical words should be used only if the inquiry is directed to a selected group to whom the language is common;

d) Questions and statements of a leading character are to be guarded against; and,

e) Complex question that require the respondent to go through several steps of reasoning before answer are undesirable.

\section{Strategy to Enhance Questionnaire Response Rate}

For reasons ranging from ignorance, carefree attitude, to lack of motivation, the targeted respondents to a questionnaire may not respond to such. It therefore becomes imperative to develop strategies to enhance response to questionnaires. A scholar ${ }^{4}$ has therefore identified seven (7) strategies to enhance questionnaire response rate which are listed hereunder;

(i) Sponsorship: a reputable and legitimate sponsor is likely to get a higher response rate than an illegitimate and disreputable one. For instance, students are more likely to respond to a questionnaire administered by their school authorities than those administered by unknown individuals or organisations;

(ii) Covering letters: questionnaires should be accompanied by persuasive covering letters or notes to respondents explaining the nature, purpose and importance of the research project, and soliciting their cooperation;

(iii) Questionnaire Format: the format of a questionnaire, namely typing, length, font, spacing etc., could also affect the response rate. Understandably, people are more likely to respond to short questionnaires than to long ones, and to neatly typed, legible and well-spaced questions than rough, illegible ones. The researcher should also limit the questions to the necessary minimum;

(iv) Ease of completion: the relative ease of completing and returning the questionnaire could also affect the response rate. Questions should be carefully worded to avoid ambiguity. When questions are ambiguous, some people may simply not complete or return the questionnaire. Detailed instructions should also be given on how to fill the questionnaire. For instance, requesting respondents to 'circle' or 'tick appropriate answer'. The researcher should also include explicit instruction on how the questionnaire should be returned, and if necessary, include a stamped, addressed envelope to minimise cost to respondent;

(v) Inducement to reply: the offer of some rewards for participating in the study could enhance the response rate. However, material inducement should be used with caution, as this may bias the study by making people overly-cooperative with the researcher;

(vi) Use of follow-up letters, telephone calls, and personal visit; and,

\footnotetext{
${ }^{1}$ Osiki, J.O., Op cit at pgs. 133-136

${ }^{2}$ Ibid

${ }^{3}$ Gasiokwu, M.O.U., Op Cit at pp.99

${ }^{4}$ Soyombo, O., Op Cit. at pp.106-108
} 
(vii) Timely delivery.

\section{Advantages of Questionnaire and Comparison with Interview}

The advantages of questionnaire some of which invariably constitute its comparison with interview are that: ${ }^{1}$

i. It is a cheaper instrument to use than an interview Schedule. For instance, there is no need to pay for services of trained interviewers. Transportation costs can also be reduced to postage cost;

ii. The questionnaire is also quicker to administer. It can be administered to large number of individuals simultaneously;

iii. The questionnaire saves the effort of call-backs if respondents are not in, as the questionnaire can be left for respondents and picked up later;

iv. The questionnaire can eliminate biasing errors that may result from personal contact between researcher and respondent because the respondent and the researcher may not have any face to face interaction;

v. The questionnaire offers greater anonymity for the subject. This can enhance the reliability of information supplied. It is generally believed that people are more frank and honest in their responses when they are anonymous. This is especially important when dealing with sensitive issues such as sexual behaviour, incomes and finances, etc.;

vi. The questionnaire does not place undue pressure on respondents to provide immediate response, as it can be completed at the respondent's convenience;

vii. The questionnaire enables respondents to secure necessary information from records or files or seek opinions of colleagues and other people, instead of making guesses; and,

viii. The questionnaire is not subject to translation biases by interviewers which may affect the study. The highly standardised wording will thus facilitate the comparison of respondents' answers, since they are all asked the same questions in the same words and in the same sequence.

\section{Disadvantages of Questionnaire}

On the other hand, the disadvantages of the questionnaire include the fact that;

i. It cannot be used with illiterates or people with low education. As a self-administered instrument, the questionnaire requires the ability to read and write;

ii. Some questions may be left unanswered by the respondent for various reasons, while the researcher will not be physically present to ensure proper completion of all relevant question;

iii. It denies the researcher the opportunity to probe for clarification or amplification of ambiguous or incomplete answers. This is important because large amount of unusable information may necessitate the rejection of a particular questionnaire(s) and may ultimately affect the reliability of the study by reducing the achieved sample size if many questionnaire are dropped;

iv. The questionnaire does not give the researcher any control over who fills the questionnaire, for instance, it may happen that a questionnaire given to a particular respondent may be given by the respondent to another person who is considered to be more knowledgeable about the issue. The information supplied may thus reflect the views of the third party rather than those of the intended respondent;

v. There is no control over the order in which the questions are answered. This will affect the reliability of information collected, especially for questionnaires which are designed such that earlier questions are answered before latter ones which may provide cues about earlier questions. For instance, an earlier question may be designed to test knowledge about an issue or product such as family planning commodities. A respondent could thus be asked to mention the types of family planning commodities that he/she knows. A latter question could be asked to assess practice of family planning by asking the respondent to identify the family planning commodities he/she ever used from a range of commodities;

vi. The researcher's knowledge is limited to the information provided by the respondent. There is no opportunity for visual observation by the researcher.

vii. The questionnaire cannot record spontaneous answers. The questionnaire could give the respondent an opportunity to reflect on his/her answers to suit the circumstances; and,

viii. The questionnaire usually has a lower response rate than the interview schedule. Some respondents may not return their questionnaires, while some returned ones may get lost in the post or in transit.

However, some of the disadvantages reveal the inadequacies of a singular method and these inadequacies can thus be controlled by combining the questionnaire method with interviews. For instance, where possible, questionnaires may be mailed and retrieved personally or delivered personally and returned by mail. In this way, the researcher can use his/her presence to assess the non-verbal behaviour of the respondent and possibly explain some things about the study to the respondent.

\footnotetext{
${ }^{1}$ Ibid, at pp. 104-106.
} 
Notable Comparisons between Interview and Questionnaire

i. They are both tools for data collection.

ii. Both are variants/forms of close-ended question.

iii. Both are survey method because they elicit direct contact between the researcher and the subject.

iv. Questionnaire precludes personal contact with respondent whereas interview elicits personal contact.

v. Questionnaire does not allow respondent to qualify ambiguous questions whereas interview makes such possible.

vi. Questionnaire provides an opportunity for respondents to give frank and anonymous answer unlike interview whereby the respondent may be bias.

vii. Questionnaire facilitates the collection of huge amount of data in a short period of time which is not possible in Interview.

viii. In Interview, people may refuse to furnish information because they were approached at the wrong time, whereas, questionnaire can be completed at the leisure of respondents.

\section{Conclusion}

The objective of this work has been to provide basic guides in the selection, construction and administration of research instruments, with special focus on the two main instruments used in research survey, namely; questionnaire and interview schedules. Their uses and limitations, as well as their construction in terms of the structure and content were also discussed. The response rate as well as the quality of information acquire will depend on the subject matter of research, the choice of the researcher and the extent to which the suggestions in this work are utilised.

\section{References}

Aboki, Y. (2009),

Akomolede, T.I. (2016),

Ayua, I.A. (2001),

Babarinde, S.A. (2006),

\section{Britten N. (1999),}

Gasiokwu, M.O.U. (2004), George S., (1960),

Hammersley, M. (1995), Khushal R., et.al. (2009),

Kvale S. (1996),

Olomolaiye, F. (1986),

Silverman D. (2000),

Soyombo, O. (2001),

Worthley, B.A. (1983),
Introduction to Legal Research Methodology, Second Edition, (Tamaza Publishing Co.Ltd, Zaria)

Types of Legal Research. M.Phil/Ph.D. Class of Legal Research Methodology Lecture notes, Tuesday $12^{\text {th }}$ January.

Legal Research and Development, in Ayua, I.A. \& Guobadia D.A. (eds), Law and Research Methodology (NIALS, Lagos).

The Link Between Everyday Reasoning, Scientific Reasoning, Scientific Research and Theory, in Methodology of Basic and Applied Research ( $2^{\text {nd }}$ ed), Postgraduate School, University of Ibadan Publication, Ibadan.

Qualitative interviews in Healthcare, In Pope C. \& Mays N., (eds.) Qualitative Research in Healthcare, $2^{\text {nd }}$ ed., London: BMY Books.

Legal Research Methodology, (Chenglo Ltd, Enugu)

Reflections on the Law of International Institutions, 13 Current Legal Problems.

Ethnography: Principles in Practice, $2^{\text {nd }}$ ed., London. Routledge.

Legal Research Methods Teaching Materials, prepared under the Sponsorship of the Justice and Legal System Research Institute. Interviews, Thousand Oaks: Sage Publications.

Research Methods and Statistics, Jos.

Doing Qualitative Research, London: Sage Publications.

Selection of Research Instruments, Questionnaire, Design and Administration, In Readings in Law and Research Methodology, I.A.Ayua and D.A. Guobadia (eds.) Lagos, Nigeria: Nigerian Institute of Advanced Legal Studies.

Some Reflections on Legal Research after Thirty Years. Silver Jubilee of the Indian Law Institute Publication No. 7, Legal Research Methodology. 